\title{
A precarização do trabalho docente no Ensino Superior: dos impasses às possibilidades de mudanças
}

\section{The precariousness of teachers' work in the Higher Education: from impasses to the possibilities of change}

\author{
Sheila Daniela Medeiros dos Santos ${ }^{1}$
}

\begin{abstract}
RESUMO
Este artigo tem por objetivo analisar o impacto do sistema de acumulação flexível e das concepções neoliberais no trabalho docente, aprofundando o estudo sobre a (re)significação dos papéis sociais de professor construídos/ negociados nas relações que se instauram na docência do Ensino Superior. Para efetivar esse estudo, foram realizadas observações em uma universidade particular situada em um município da região de Campinas. As análises do material empírico, a partir dos pressupostos teórico-metodológicos de Antunes e Vygotsky, mostraram que nos conflitos e tensões da cotidianidade do trabalho docente emergem complexos movimentos de fuga, mas também de enfrentamento e ruptura, que promovem o dissenso resgatando o compromisso social coletivo e o devido reconhecimento dos direitos fundamentais de todo e qualquer ser humano à cidadania.
\end{abstract}

Palavras-chave: acumulação flexível; trabalho docente; Ensino Superior; papéis sociais.

\footnotetext{
ABSTRACT

This article aims to examine the impact of the system of flexible accumulation and neoliberal ideas in the teachers' work deepening the study about

${ }^{1}$ Doutora em Educação pela Universidade Estadual de Campinas (UNICAMP) e docente da Faculdade de Educação da Universidade Federal de Goiás (UFG). E-mail: sheiladaniela@
} yahoo.com.br 
the (re)signification of the social roles of teachers constructed/negotiated in relations which are established in the teaching of Higher Education. To carry out this study, observations were made at a private university located in a municipality in the region of Campinas. The analyses of empirical material from the theoretical and methodological assumptions by Antunes and Vygotsky showed that in the conflicts and tensions of the routine of teachers' work complex movements of escape emerge, but also of confrontation and disruption, advancing the dissent, rescuing the collective social commitment and rightful recognition of the fundamental rights of every human being to their citizenship.

Keywords: flexible accumulation; teachers' work; Higher Education; social roles.

\section{Introdução}

Na passagem para o século XIX, na Europa, a emergência do processo de industrialização e o avanço das relações capitalistas de produção promoveram transformações sociais, econômicas, políticas e culturais que marcaram de modo significativo a história da humanidade.

Esse processo, de acordo com Engels (1988), desde seu início apresentou grande complexidade, pois, além de buscar incessantemente o acúmulo do capital através do sistema de fábrica e do trabalho assalariado, ainda incluía aspectos tais como: a urbanização, as inovações tecnológicas no domínio da produção, o desenvolvimento do comércio, a criação das classes sociais, a migração do campo para a cidade, a explosão demográfica, as novas formas de divisão do trabalho e as alterações na qualidade das relações sociais.

Segundo Hobsbawm (1982), as relações sociais que foram se configurando no modo de produção capitalista apresentavam a marca de uma cisão que expressava a divisão entre os que eram proprietários dos instrumentos e dos meios de produção e aqueles que, não sendo proprietários, dispunham apenas da sua força de trabalho, transformada em mercadoria.

Como a maior parte da massa populacional não encontrou espaço no mercado de trabalho, tornou-se excedente e disponível, constituindo, na expressão de Marx (1985), o "exército industrial de reserva".

Nesse cenário, com o passar do tempo, se por um lado o aumento da produtividade promovido pelas inovações tecnológicas restringiu a necessidade de 
mão de obra, expandindo o exército industrial de reserva, por outro incorporou à produção capitalista diferentes áreas e funções que exigiam certa qualificação. ${ }^{2}$

Marx (1985), no século XIX, ressaltou o quanto o trabalho humano tornou-se imprescindível à reprodução e à autovalorização do capital, às formas de intensificação e de extração da mais-valia - lógica que, conforme Antunes (2000, p. 119) bem observou, permanece inalterada na sociedade contemporânea, ainda que a classe trabalhadora esteja vivenciando a precarização do trabalho e o vertiginoso crescimento do desemprego estrutural, acompanhado do fenômeno de exclusão social.

De acordo com Antunes (1999), ao longo do século XX, o binômio taylorismo/fordismo, caracterizado basicamente pela produção em massa, pelas unidades produtivas concentradas e verticalizadas, pelo controle rígido dos tempos e dos movimentos e pelo desenvolvimento fabril sob forte despotismo, começou a ser crescentemente substituído pelas formas produtivas flexibilizadas e desregulamentadas, das quais o capitalismo monopolista do Japão ou toyotismo tornou-se um exemplo.

Embora os princípios da acumulação flexível ou toyotismo tenham adquirido supremacia, é possível observar, nos dias de hoje, que os modos de organização e gestão do trabalho, fundamentados no taylorismo e no fordismo, também convivem lado a lado com esse modelo de comportamento organizacional emergente.

O fato é que o capitalismo, principalmente a partir da superautomação, da robótica, da informatização, da internet, entrou em um quadro crítico de complexidade, gerando profundas mudanças no interior do mundo do trabalho.

Essa situação, decretada pelo progresso científico e tecnológico e pela crise inevitável do capitalismo, levou alguns autores (GORZ, 1993; OFFE, 1989; RIFKIN, 1996) a postularem o fim do mundo do trabalho.

No entanto, em sentido contrário às teses que advogam o fim do trabalho e da classe trabalhadora, Antunes (1999) afirma que as novas conquistas tecnológicas, as exigências da mundialização/globalização e as formas atuais de gestão empresarial parecem visar não mais à extensão do processo de industrialização, mas ao seu aprofundamento.

\footnotetext{
${ }^{2}$ Em uma sociedade cindida entre aqueles que detêm e os que não detêm os meios de produção, o conhecimento torna-se propriedade privada de uma classe política e economicamente favorecida. Aí reside um paradoxo (aparente) que se insere na essência do capitalismo: "O trabalhador não pode ter o meio de produção, nem deter o saber; mas sem ele, também não pode produzir, porque para transformar a matéria precisa dominar algum tipo de saber" (SAVIANI, 2000, p. 163). Desse modo, o trabalhador atinge, pouco a pouco, apenas o patamar mínimo de qualificação geral, pelo fato de apreender somente o indispensável exigido para operar as máquinas informatizadas que são introduzidas no processo de produção.
} 
Nesse sentido, o capital pode diminuir o trabalho vivo, desempregar parcelas imensas da população e intensificar sua utilização, mas não pode, de modo algum, eliminá-lo, uma vez que a extinção do trabalho - incluindo o enorme contingente de trabalhadores dos países do Terceiro Mundo - suporia "a destruição da própria economia de mercado, pela incapacidade de integralização do processo de acumulação de capital" (ANTUNES, 1999, p. 186).

Essa análise que afirma não a eliminação, mas "as metamorfoses do mundo do trabalho", evidencia a importância de investigar o modo como essas transformações afetam o movimento social e político dos trabalhadores.

No rastro dessa discussão, a classe trabalhadora de diversos países vê ruir o acesso a alguns bens considerados essenciais (alimentação, habitação, educação, saúde, segurança, justiça) com a falência do welfare state.

No Brasil, a situação agrava-se ainda mais, uma vez que, diferente do mundo europeu, essa política de governo praticamente não teve expressão em nosso país.

Por conseguinte, principalmente a partir da década de 1990, na conjuntura da globalização e das reformas neoliberais com políticas deliberadas que diluem as fronteiras entre o público e o privado, os brasileiros experienciam no campo do trabalho o acirramento das privatizações, a reestruturação industrial, as terceirizações, o desemprego, a superexploração, o aumento do emprego informal e a fragilização do poder sindical. Sem contar que, no cenário nacional, assistimos ao (re)aparecimento de práticas variadas de discriminação e segregação que (re) afirmam antigos estereótipos étnicos, sociais, culturais e de gênero.

Nesse contexto, de forma compatível com o ideário neoliberal, a ética individualista e a competitividade são reforçadas mediante "a aquisição/o acúmulo de competências" que (supostamente) garantam a "empregabilidade", em tempos de desemprego e de exclusão para a maioria.

A lógica do mérito e da competência se alastra vertiginosamente, sendo a competição uma prática bastante comum na condução de todo esse processo. O desejo de vencer e obter sucesso torna-se uma obsessão que requer do indivíduo um trabalho extra sem limites, que se estende para além dos muros das organizações, levando-o a disputar espaços da vida pessoal e familiar, com implicações de diversas ordens.

Segundo Saviani (2003, p. 150), o trabalhador, induzido a pensar que o seu sucesso resulta do sucesso da empresa, aumenta o seu empenho e a sua participação nas responsabilidades da organização e não percebe que, ao constituir mão de obra manipulável, é levado a trabalhar mais por muito menos, ou seja, por salários cada vez mais baixos.

Esse modo de pensar, que surge a partir de procedimentos de gestão que se dizem "democráticos", na realidade, corresponde às imposições reiteradas 
para ocultar as contradições existentes no sistema de produção capitalista, para acirrar a competição interna/externa e para expropriar a subjetividade dos trabalhadores durante $\mathrm{o}$ ato de produção.

Nessa ambiência, os homens voltam-se uns contra os outros, aprofundando o individualismo, neutralizando a mobilização coletiva e perdendo o poder de luta ao deixarem de assumir uma perspectiva classista em defesa dos direitos universais.

Portanto, a integração política, econômica e social (acesso às políticas públicas) está em profundo descompasso, uma vez que a maior parte da população conta apenas com os resquícios do espaço político, pelo fato de ser restrito ao direito de voto e ao saber alienado.

Desse modo, apesar de a história da democracia no Brasil apontar para importantes ganhos políticos, em especial a inclusão do voto dos analfabetos e a redução da desigualdade política entre os setores urbanos e rurais, é possível notar que o período de maior extensão da democracia corresponde, na verdade, ao seu estreitamento: de um lado, ocorre a ampliação da cidadania política (direito de voto) e, de outro, ocorre a ausência da participação popular nos foros de decisão governamental, já que isso não é interessante para as classes dominantes.

Portanto, se no nível político ocorre uma espécie de vácuo na democracia, no nível cultural e social o trabalho, base de constituição das identidades individuais e coletivas, ao perder centralidade, deixa à deriva sujeitos que se veem isolados e incapazes de atribuir sentido à sua existência.

\section{As interfaces do trabalho docente no Ensino Superior}

A economia capitalista flexível, como não poderia deixar de ser, repercutiu fortemente no campo educacional.

No âmbito desse sistema, como a escola é vista como um locus de formação profissional, a promessa da empregabilidade (GENTILI, 2002, p. 51) é guiada pela ênfase nas capacidades e competências que cada pessoa deve adquirir no mercado educacional para atingir uma melhor posição no mercado de trabalho.

Para sustentar essa lógica, vários mecanismos de avaliação do sistema educativo têm sido implementados pelas políticas governamentais para orientar o consumidor e ajudá-lo a escolher "a melhor" instituição de ensino. Avaliações técnicas dessa natureza sustentam-se na necessidade de comparações e rankings e buscam o controle da qualidade dos serviços educacionais, tal como ocorre no mundo empresarial. Sem contar que palavras usuais nesse campo passam, 
cada vez mais, a fazer parte dos planos e projetos pedagógicos: produtividade, eficiência, eficácia, gestão por metas, gerenciamento, feedback... Essas expressões, tecidas com vistas a reproduzir o capital flexível, afetam a escola, a universidade, os alunos, os professores.

Uma importante contribuição para o entendimento dessa problemática é dada por Kuenzer (2002, p. 93), quando analisa a nova relação entre o mundo do trabalho e a educação, introduzindo à discussão os conceitos de "exclusão includente" e "inclusão excludente".

De acordo com Kuenzer (2002), a "exclusão includente" refere-se às estratégias para excluir o trabalhador do mercado formal e incluí-lo de forma precarizada através de mecanismos tais como: a (re)contratação do trabalhador com salários mais baixos na própria empresa (mesmo que tenha registro em carteira) e/ou através de empresas terceirizadas; a prestação de serviços como autônomo; a ampliação escamoteada da jornada de trabalho; a ameaça constante de demissão; a crescente concorrência entre os trabalhadores; e o aumento da insegurança quanto à permanência no emprego.

Já a "inclusão excludente" é uma lógica que diz respeito ao investimento neoliberal de inclusão na educação a partir de estratégias tais como: a formação aligeirada em instituições superiores de idoneidade discutível; o ensino a distância; o enxugamento dos currículos, dentre outros. Essas modalidades de (aparente) inclusão no campo educacional fornecem a justificativa, pela incompetência, para a exclusão do mundo do trabalho, dos direitos e das formas dignas de existência.

Desse modo, os diversos aspectos de "exclusão includente", ao se articularem dialeticamente às estratégias de "inclusão excludente", fornecem ao capital flexível a força de trabalho que lhe convém.

Pode-se depreender dessas discussões que, no Brasil contemporâneo, o trabalho docente inscreve-se em meio a duas problemáticas centrais: a primeira refere-se às transformações que estão ocorrendo no mundo do trabalho devido à nova configuração que o capitalismo vem assumindo nas últimas décadas, no que diz respeito à sua estrutura produtiva e ao seu universo de ideários e valores; e a segunda refere-se a uma série de medidas que, geralmente denominadas como "reformas", afirmam-se sob a hegemonia das concepções neoliberais e redefinem o papel do Estado na sua relação com a educação. ${ }^{3}$

${ }^{3} \mathrm{Na}$ sociedade brasileira contemporânea assistimos ao enfraquecimento do Estado pelo fato de não atender às expectativas da população crescentemente expulsa do mercado de trabalho e privada de seus direitos sociais e, ainda, pelo fato de se mostrar incapaz de possibilitar o acesso a uma educação de qualidade para toda a população. 
Essas reformas, que surgem em caráter emergencial com o intuito de reduzir as distâncias sociais, de acordo com Frigotto (2001), além de não trazerem mudanças estruturais à sociedade brasileira, ainda legitimam formas de segregação e exclusão, uma vez que são baseadas no princípio da formulação de políticas diferentes para os "desiguais" e da orientação para o mercado e para a estratégia política de redução do Estado. Em outros termos, somos cada vez mais oprimidos pelo peso das políticas compensatórias e assistencialistas, impostas pelo governo sob a pressão daqueles que detêm os meios de produção.

Nessa ambiência, surgem velhas e novas questões, para as quais muitas respostas disponíveis ainda não são satisfatórias: A que novas formas de expropriação os professores do Ensino Superior estão submetidos como trabalhadores? Qual o impacto das concepções neoliberais nas relações que se instauram entre professor/aluno no Ensino Superior? De que modo os papéis sociais dos professores são construídos e negociados nessas relações?

Com o intuito de buscar respostas para essas questões, procurou-se observar durante seis meses, no período noturno, uma universidade da rede privada situada em um município próximo à região de Campinas.

As observações das situações recorrentes e/ou peculiares que ocorreram na vida diária da instituição, bem como as entrevistas e as conversas informais com os atores sociais envolvidos no processo da pesquisa, foram registradas em diários de campo. Esse material empírico, tal como preconiza a pesquisa em Educação numa abordagem qualitativa, foi devidamente organizado a partir de categorias de análise, construídas na dinâmica interativa e discursiva, tecida e materializada nas/pelas relações sociais.

A opção por uma universidade particular justifica-se não apenas pelo fato de a precarização do trabalho repercutir de forma ainda mais acentuada nas instituições de Ensino Superior da rede privada, mas também devido às transformações relativas ao processo de expansão dessas instituições no Brasil a partir de 1990.

Os dados estatísticos do Instituto Nacional de Pesquisas e Estudos Educacionais Anísio Teixeira (INEP) contabilizaram em 2006, por intermédio do Sistema Nacional de Avaliação da Educação Superior (SINAES), 2.398 instituições de Ensino Superior, sendo 257 públicas (60 municipais, 92 estaduais e 105 federais) e 2.141 particulares.

Segundo Minto e Muranaka (2002), a diversificação e a diferenciação das instituições de Ensino Superior, com a criação e o crescimento de instituições privadas, na lógica capitalista, revelam a intenção do governo em manter, de um lado, alguns poucos "Centros de Excelência", responsáveis pela tríade ensino/ pesquisa/extensão, e, de outro lado, os muitos "escolões de $3^{\circ}$ grau", locais de treinamento e profissionalização para o mercado de trabalho. 
Conforme Mészáros (1981) bem observou, o número crescente de diplomas de nível superior, atualmente, revela não a expansão de vagas no ensino público, mas a abertura de cursos de graduação e pós-graduação (lato e stricto sensu) de iniciativa privada e a implantação do ensino a distância. Segundo este autor, obviamente, trata-se da massificação sob o disfarce da democratização. ${ }^{4}$

O desenho desse quadro aponta para um modelo de educação mercantilista e instrumental, com predominância do ensino virtual, dos modelos de franchising educacional, das avaliações baseadas em critérios quantitativos, da ruptura com a produção de conhecimentos críticos, da formação aligeirada e da ênfase em uma educação estritamente conformista para uma inserção social sem autonomia.

Barreto (2001) critica a lógica utilitária imposta às práticas pedagógicas na atual configuração das novas tecnologias, uma vez que os materiais didáticos podem ser utilizados de forma simplista, desapropriando o trabalho do professor e a formação educativa, tornando-a cada vez mais imediatista.

Ampliando, nota-se nas universidades privadas a predominância de uma nova realidade: a demissão de professores doutores de mais larga experiência, cedendo lugar à contratação de especialistas e graduados; a rotatividade de docentes contratados temporariamente; a ênfase na lógica "menos professores, mais alunos"; o rebaixamento das remunerações, sem perspectivas de recuperação de perdas salariais; o desempenho acadêmico baseado na lógica produtivista, a qual dificulta a realização de práticas que visam à transformação social e à indissociabilidade entre ensino, pesquisa e extensão.

Como as instituições públicas realizam poucos concursos para o ingresso na carreira docente, e estes, quando ocorrem, na maioria das vezes são em caráter de substituição, as instituições particulares constituem para muitos professores uma "alternativa" para a complementação salarial ou a única fonte de renda. Nesse caso, como o valor hora-aula costuma ser baixo, o docente vincula-se a diferentes instituições de ensino, simultaneamente, ministrando várias disciplinas (algumas delas incompatíveis com a sua formação acadêmica) e deslocando-se de um extremo a outro para poder cumprir a sua jornada de trabalho.

Além disso, nas instituições privadas, os professores vivenciam uma realidade extenuante marcada: pelo medo constante do desemprego; pela ausência de garantia de seus direitos sociais; pela impossibilidade de construção de uma carreira; pela sua desvalorização social; pela perseguição às práticas de organização sindical; pela submissão ao poder do "cliente" (no espaço acadêmico

\footnotetext{
${ }^{4}$ Nesse contexto, há de se registrar a política de desmonte das universidades públicas inserida em projetos específicos das elites dominantes que historicamente controlam o Estado brasileiro e que estão associadas a grupos capitalistas mundiais.
} 
da rede particular também se difunde a máxima empresarial: "o cliente tem sempre razão"); pelas represálias ao exercerem a autonomia e a expressão de suas ideias; e pela estranha exigência de se transformarem em "animadores de auditório" e de ministrarem "aulas-show" que tornam o seu "produto" (ensino) mais atraente, de fácil apreensão e em consonância com as exigências do mercado. Todos esses elementos impactam o trabalho docente, com consequências devastadoras de diversas ordens, tanto para os professores quanto para os alunos e a sociedade de um modo geral.

Essa situação, ao inviabilizar a preparação criteriosa de aulas que visam a uma discussão política e epistemológica, ao desenvolvimento de projetos de pesquisa e de extensão e, ainda, à realização de um trabalho acadêmico digno, acaba propiciando práticas que contradizem discursos.

\section{Lógica meritocrática, produtividade e trabalho docente}

A crescente mercantilização do setor privado de educação superior impõe cada vez mais barreiras ao trabalho docente. O professor também é afetado pelo aumento de exigências em relação à sua qualificação e à sua competência. No contexto universitário atual, os docentes não se reconhecem enquanto unidade e disputam cada mísero recurso disponibilizado para pesquisa pelas agências de fomento.

Desse modo, se por um lado o avanço tecnológico acelerou a produção acadêmica e proporcionou a divulgação de uma enorme quantidade de informações, por outro lado trouxe a superficialidade e a repetição, a partir de "conhecimentos requentados" (MANCEBO, 2004) ou rapidamente produzidos para publicação.

Segundo Pinheiro (2001), de acordo com a lógica meritocrática e mercadológica, os professores são avaliados e valorizados através de um critério de produtividade expresso pela quantidade de produções e pela pontuação a elas atribuídas, muitas vezes sem que haja uma avaliação atenta acerca da qualidade de tais produções.

Mancebo (2003, p. 20) expressa preocupação diante dessa situação em que a dimensão crítica é subtraída da produção de conhecimento, do campo da política e da ética que envolvem o trabalho docente.

Uma outra faceta dessa realidade é a busca de saídas individuais e a perigosa difusão do empreendedorismo entre docentes, como forma de acrescentar outras fontes de renda às baixas remunerações, a partir de consultorias, de aulas particulares e da "venda de serviços acadêmicos". 
Dentro dessa conjuntura, constata-se ainda o surgimento de posturas inescrupulosas. Uma delas se refere ao fato de professores (até mesmo mestres e doutores!) se organizarem em grupos para vencerem a corrida do maior número de publicações e participações em eventos científicos possíveis, de tal forma que cada integrante produza um texto colocando o nome dos demais como autores, ao invés de produzirem, de fato, o trabalho acadêmico em conjunto. A outra se refere ao fato de professores de universidades particulares elaborarem trabalhos acadêmicos (resenhas, relatórios de estágio, artigos, trabalhos de conclusão de curso) para venderem aos alunos de outras universidades diferentes daquelas em que trabalham, criando, para isso, um banco de dados com os nomes dos alunos, das universidades e dos professores que solicitam os trabalhos, para que não ocorra a venda de um trabalho para o mesmo professor ou a mesma universidade, já que um trabalho é vendido várias vezes com pequenas alterações.

Como as intensas transformações do atual estágio do capitalismo são apreendidas pela sociedade sem maiores questionamentos, os novos padrões de sociabilidade, pautados nas relações mercantis, surgem como convite ao professor para desenvolver um trabalho alienado, vendendo sua força de trabalho sob condições que the são impostas ou sacrificando-se ao consumo de prestígio exigido pela lei do mercado.

É nesse contexto que o trabalho docente se insere atualmente, balizado pelas atuais demandas do capitalismo, pelas pressões da cobrança de níveis mais elevados de qualificação, pela proletarização da profissão docente e pela precarização das condições de trabalho.

Nesse momento, surgem outras questões: de que modo a autonomia e o sentido de trabalho dos docentes nas instituições de Ensino Superior particular podem ser resgatados? De que modo os movimentos sociais de interesses e lutas comuns entre os docentes e entre eles e os alunos podem ser articulados? De que modo as concepções de homem, de mundo e de sociedade, que favorecem mudanças, podem ser defendidas/promovidas pelos docentes no contexto da atual reestruturação produtiva?

\section{Significado e sentido do trabalho docente}

Oliveira (2004), ao debruçar-se nas análises desenvolvidas em pesquisas a respeito do trabalho docente, conclui que, especialmente nos anos 1990 e no contexto das reformas implementadas, ocorreu um deslocamento temático do estudo sobre o "trabalho docente" na direção do estudo sobre a "formação 
docente", não apenas marcando o lugar pouco central da categoria trabalho no campo da educação brasileira, mas também produzindo uma lacuna que refletia as concepções dominantes em nossa sociedade.

Para Marx (2004), o trabalho, ${ }^{5}$ além de prover as condições materiais de existência, produz, ao mesmo tempo, a condição humana. O processo de trabalho (transformação da natureza) é privilegiado nas relações homem/mundo, relações que instituem/são instituídas a(na) vida social, histórica, política, econômica e cultural.

No entanto, segundo Marx (2004), o trabalho, sob relações de dominação, impõe-se ao homem não como atividade que desenvolve capacidades e cria novas necessidades, não como essência humana, mas como atividade que tem como único sentido a sobrevivência física.

Nessas condições, o trabalho torna-se estranhado (MARX, 1985), ou seja, o homem se aliena no trabalho e cria coisas que lhe escapam e se mostram estranhas à produção histórica da consciência humana.

Considerando essas premissas, para vislumbrar possíveis caminhos que conduzam a mudanças, é necessário aprofundar a análise sobre as relações entre as condições subjetivas e as condições objetivas imbricadas no trabalho docente.

Os pressupostos teórico-metodológicos de Vygotsky $(1994,1995)$ e Leontiev (1978), ancorados na perspectiva histórico-cultural em Psicologia, cujas premissas básicas são fundamentadas no materialismo histórico e dialético de Marx e Engels, apontam para a possibilidade de olhar o real e ir além das aparências, desvelando a essência das contradições e avançando teoricamente em termos qualitativos.

Segundo Leontiev (1978), as condições subjetivas são próprias do trabalho humano, pois este se constitui numa atividade consciente. No entanto, na sociedade capitalista, estas condições podem ser afetadas, dependendo do grau de objetivação do processo de trabalho em que o homem está envolvido.

Enquanto o processo de trabalho produtivo é altamente objetivado pelo fato de gerar diretamente mais-valia e comprometer a autonomia do operário na execução de suas tarefas, no caso do trabalho docente o processo não se objetiva na mesma proporção, deixando uma margem de autonomia maior, pois o professor tem a possibilidade de optar por metodologias, de selecionar

${ }^{5} \mathrm{O}$ conceito de trabalho, no sentido proposto por Marx (1985), pode ser distinguido como trabalho produtivo e trabalho improdutivo ao capital, embora os limites entre eles estejam, atualmente, cada vez mais frágeis. Todo trabalhador produtivo é assalariado, mas nem todo assalariado é trabalhador produtivo. Quando o trabalho não produz mais-valia para o capital, não é trabalho produtivo. Essa distinção mostra que um mesmo trabalho pode ser produtivo e improdutivo, dependendo de sua subordinação ao capital. 
conteúdos, de escolher atividades pedagógicas e, principalmente, de dificultar as ações do Estado na tentativa de controlar o seu trabalho.

Desse modo, conforme Enguita (1991) e Apple (1987) bem observaram, na atividade de ensino, embora não se possa negar as transformações ocorridas devido à vinculação às formas capitalistas de produção, o processo de depreciação do trabalho docente não ocorre com a mesma intensidade e também não é tão devastador, no que diz respeito à autonomia e à participação política e social, quanto o processo de desqualificação do operário no âmbito do trabalho diretamente produtivo.

Pelo que foi exposto, nota-se que as condições objetivas e as condições subjetivas do trabalho docente podem ser compreendidas a partir das discussões sobre o significado e o sentido atribuídos ao papel de professor na sociedade atual.

Segundo Leontiev (1978), o significado expressa a realidade independentemente da relação individual que o homem mantém com a mesma. Desse modo, o significado expressa o sistema de relações concretas que se formou no processo de desenvolvimento de determinado papel social, apresentando um núcleo relativamente estável que se refere à generalização e à fixação da prática social humana.

No caso, o significado do papel de professor é construído historicamente e atribuído convencionalmente pela sociedade, consistindo um ponto central de compreensão compartilhado por todas as pessoas que a esse papel se referem.

De acordo com Vygotsky (1995), no decorrer da experiência social o homem procura compreender a realidade, expressar seus sentimentos, fazer uso dos signos, criar modos de agir, de pensar e de falar que se transformam com o desenvolvimento das relações sociais. Nesse contexto, o homem vai legitimando papéis sociais e fixando funções para desempenhar tais papéis.

O sentido, por sua vez, refere-se ao significado desse papel para cada sujeito e é composto por relações que dizem respeito ao contexto de vivência desse papel e à experiência pessoal, de natureza social. Essa experiência é sempre mais complexa do que a generalização contida nos significados. Assim, os papéis sociais existentes em determinada sociedade procuram fornecer às ações um sentido correspondente ao seu significado.

No entanto, como o sentido se alimenta da experiência coletiva da humanidade e emerge nas/das práticas sociais, com o tempo, pode alterar o significado estabelecido nas situações concretas. Trata-se de uma relação dialética em que o significado pode modificar o sentido, ao mesmo tempo em que o sentido pode modificar o significado.

Desse modo, o significado do papel de professor é formado pelo conteúdo concreto efetivado através da ação de ensinar, considerando as condições 
reais e concretas da mediação que se estabelecem com o outro no processo de apropriação do conhecimento.

Nesse movimento incessante, os papéis sociais desempenhados pelos docentes das instituições de Ensino Superior vão se constituindo, se fixando e/ ou se transformando na interseção das relações sociais.

Considerando este referencial, quando o sentido do papel social que o professor ocupa não corresponder ao significado dado pelo conteúdo efetivo desse papel determinado pela sociedade, ocorre uma ruptura entre significado e sentido, tornando o trabalho docente alienado ou não, o que dependerá do conteúdo implícito no significado e no sentido, que pode surgir com vistas à emancipação, fortalecendo as classes trabalhadoras, ou pode se estabelecer com vistas ao conformismo e à alienação, favorecendo as classes dominantes.

Se o sentido do papel social docente atribuído pelo professor que o desempenha for apenas o de garantir a sua sobrevivência, ou seja, o de trabalhar somente pelo salário, e o significado do papel de professor fixado socialmente expressar as ações concretas de um profissional que ensina, ao mesmo tempo em que aprende com seus alunos, de um profissional que tem a responsabilidade política e social para construir um projeto de formação emancipatória, haverá a cisão entre significado e sentido. Nesse caso, o trabalho alienado do docente poderá descaracterizar a prática educativa, comprometer a qualidade do ensino e, com o tempo, alterar o significado do papel social de professor mencionado. Do mesmo modo, tal alteração pode ocorrer se for o caso contrário.

Os papéis sociais referentes ao trabalho docente que procuram superar em algum grau a alienação não dependem apenas das condições subjetivas (visão de mundo do professor que abrange a compreensão dos objetivos de sua ação de ensinar), mas dependem, também, das circunstâncias ou condições efetivas de trabalho ${ }^{6}$ que fazem a mediação entre uma esfera e outra.

Quando essas condições objetivas de trabalho não permitem que o professor se realize como ser humano, conduzindo com autonomia suas ações, criando necessidades de outro nível e possibilitando satisfazê-las (MARX, 2004), este trabalho é realizado na situação da alienação.

Os docentes que compreendem a relação imbricada entre o significado e o sentido atribuídos ao papel social de professor, e impregnados de um conteúdo ideológico que traduz os interesses das camadas populares, lutam por melhores

${ }^{6}$ Essas condições referem-se aos recursos físicos do ambiente de trabalho, aos materiais didáticos, ao modelo de gestão, às possibilidades de trocas de experiência, aos baixos salários, à duração da jornada e ao tipo de contrato de trabalho, ao tempo disponível para a preparação de aula e para a atualização, entre outros aspectos. 
condições objetivas de trabalho, procurando concretizar uma prática pedagógica não alienante.

A articulação dialética entre as condições objetivas e as condições subjetivas de trabalho, bem como as relações entre as categorias significado e sentido, apresenta-se como um caminho promissor para a compreensão do trabalho docente e para o delineamento de possíveis intervenções, visando ampliar a problematização da realidade e o enfrentamento coletivo dos aspectos que obstaculizam a produção de um conhecimento crítico.

\section{Considerações finais}

$\mathrm{Na}$ enorme quantidade de transformações a que assistimos, os sinais são contraditórios. Assim, o poder do dinheiro que quantifica e confere a tudo, ou a quase tudo, o valor de mercadoria a ser comprada e consumida, invade as esferas da vida humana, fazendo com que as relações entre as pessoas, apagadas pela lógica capitalista, pareçam coisas.

No contexto do capitalismo tardio, ${ }^{7}$ mercantiliza-se de forma aguda a vida social, a educação e o trabalho docente, fragilizando-o e fragmentando-o.

Compreender a natureza do trabalho docente no Ensino Superior em sua articulação com a dinâmica social no contexto do avanço da globalização constitui um desafio, pois o discurso neoliberal, expressão ideológica do momento atual, direciona as análises da realidade para a superfície dos fenômenos sociais, dificultando a compreensão do modo como se configura a exploração do homem pelo homem, impedindo a organização dos movimentos sociais coletivos e fazendo desaparecer o sujeito concreto e histórico.

Essa análise nos motiva a pensar sobre a educação desqualificada e precária aos interesses do capital. Incentiva, também, a refletir sobre o papel da universidade e o trabalho docente como possibilidade concreta de mediação dos interesses da maioria discriminada, exatamente porque a prática pedagógica é prática contraditória, que emerge em meio a conflitos e tensões da cotidianidade e que incita complexos movimentos, ora de fuga, ora de enfrentamento e ruptura frente às condições adversas.

${ }^{7}$ A expressão "capitalismo tardio" não significa o envelhecimento, o colapso ou o fim de um sistema que parece ultrapassado, mas traduz a ideia de expansão das transnacionais, a globalização dos mercados e do trabalho, o consumo de massa, o desenvolvimento tecnológico, a intensificação dos fluxos internacionais do capital, a terceirização, a redução do emprego. 
Portanto, o desafio está exatamente na capacidade de construir conhecimentos a partir das transformações atuais. O sinal de alerta, a exclusão social, ${ }^{8}$ já é mais que suficiente para justificar a premência em criar propostas alternativas que apontem caminhos viáveis para a construção de uma sociedade não excludente.

Analisar o trabalho docente no Ensino Superior a partir das questões nucleares colocadas através desse trabalho é um modo de promover o dissenso, não apenas desafiando o paradigma de cunho neoliberal que quer se impor como pensamento único, mas principalmente resgatando o compromisso social coletivo e o devido reconhecimento dos direitos fundamentais de todo e qualquer ser humano à cidadania.

\section{REFERÊNCIAS}

ANTUNES, R. Adeus ao trabalho? Ensaio sobre as metamorfoses e a centralidade do mundo do trabalho. São Paulo: Cortez, 1999.

. Os sentidos do trabalho: ensaios sobre a afirmação e a negação do trabalho. São Paulo: Boitempo, 2000.

APPLE, M. W. Relações de classe e de gênero e modificações no processo de trabalho docente. Cadernos de Pesquisa, São Paulo, n. 60, fev. 1987.

BARRETO, R. G. Educação a distância: uma aproximação. Universidade e Sociedade, Brasília, ano X, n. 23, p. 153-159, fev. 2001.

ENGELS, F. A situação da classe trabalhadora na Inglaterra. São Paulo: Global, 1988.

ENGUITA, M. F. A ambiguidade da docência: entre o profissionalismo e a proletarização. Teoria \& Educação, Porto Alegre, n. 4, 1991.

FRIGOTTO, G. A produtividade da escola improdutiva: um reexame das relações entre educação e estrutura econômico-social capitalista. São Paulo: Cortez, 2001.

GENTILI, P. Três teses sobre a relação trabalho e educação em tempos neoliberais. In: LOMBARDI, J. C.; SAVIANI, D.; SANFELICE, J. L. (Orgs.). Capitalismo, trabalho e educação. Campinas: Autores Associados, HISTEDBR, 2002. (Coleção Educação Contemporânea).

GORZ, A. O declínio da relevância do trabalho e a ascensão de valores pós-econômicos. O socialismo do futuro, Salvador, n. 6, 1993.

${ }^{8}$ Obviamente, a questão da exclusão social no mundo contemporâneo ganharia consistência se considerada sob a convergência de três aspectos: a mundialização, as metamorfoses no processo de trabalho e a democracia. 
HOBSBAWM, E. A era das revoluções. Rio de Janeiro: Paz e Terra, 1979. . A era do capital. Rio de Janeiro: Paz e Terra, 1982.

KUENZER, A. Exclusão includente e inclusão excludente: a nova forma de dualidade estrutural que objetiva as novas relações entre educação e trabalho. In: LOMBARDI, J. C.; SAVIANI, D.; SANFELICE, J. L. (Orgs.). Capitalismo, trabalho e educação. Campinas: Autores Associados, HISTEDBR, 2002. (Coleção Educação Contemporânea).

LEONTIEV, A. O desenvolvimento do psiquismo. Lisboa: Horizonte, 1978.

MANCEBO, D. Trabalho docente: políticas e subjetividade. Projeto de pesquisa - Universidade do Estado do Rio de Janeiro - UERJ. Rio de Janeiro, 2003.

. Uma análise da produção escrita sobre o trabalho docente em tempos de globalização. In: _ _ FÁVERO, M. L. A. (Orgs.). Universidade: políticas, avaliação e trabalho docente. São Paulo: Cortez, 2004.

MARX, K. O Capital. 2. ed. São Paulo: Nova Cultural, 1985.

. Manuscritos econômico-filosóficos. São Paulo: Boitempo, 2004.

MÉSZÁROS, I. Marx: a teoria da alienação. Rio de Janeiro: Zahar, 1981.

MINTO, C. A.; MURANAKA, M. A. S. Políticas públicas atuais para a formação de profissionais em educação no Brasil. Universidade e Sociedade, Brasília, ano XI, n. 26, p. 134-143, fev. 2002.

OFFE, C. Trabalho e sociedade: problemas estruturais e perspectivas para o futuro da sociedade do trabalho. Rio de Janeiro: Tempo Brasileiro, 1989.

OLIVEIRA, D. A. et al. Cambios en la organización del trabajo docente - consecuencias para los profesores - Publicação em Espanhol. Revista Mexicana de Investigación Educativa, México, v. 9, n. 20, p. 183-197, jan./mar. 2004.

PINHEIRO, M. Fragmentos para uma práxis da universidade cidadã. Universidade e Sociedade, Brasília, ano X, n. 23, p. 160-164, fev. 2001.

RIFKIN, J. O fim dos empregos: o declínio inevitável dos níveis dos empregos e a redução da força global de trabalho. São Paulo: Makron Books, 1996.

SAVIANI, D. Do senso comum à consciência filosófica. 13 ed. Campinas: Autores Associados, 2000.

. O choque teórico da politecnia. Trabalho, Educação e Saúde, Rio de Janeiro:

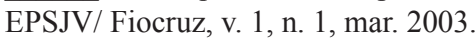

VYGOTSKY, L. S. A formação social da mente. São Paulo: Martins Fontes, 1994.

. Pensamento e linguagem. São Paulo: Martins Fontes, 1995.

Texto recebido em 29 de janeiro de 2010.

Texto aprovado em 07 de fevereiro de 2010. 